\title{
Factors influencing visual outcome after cataract extraction among Arabs in Kuwait
}

\author{
MAHMOUD AL SALEM AND LINA ISMAIL \\ From the Eye Department, Ibn-Sina Hospital, Kuwait, Arabian Gulf
}

SUmmary Of 409 consecutive Arab patients in Kuwait who had extractions for idiopathic (senile and presenile) cataract 385 were followed up for a minimum period of one year. Among these the final visual outcome was $6 / 12$ or better in 208 eyes (54\%) but visual acuity was $6 / 18$ or less in 177 eyes $(46 \%)$. Of these 177 eyes 127 eyes $(71 \cdot 8 \%)$ had poor vision due to preoperative ocular disorders and $31(17 \cdot 5 \%)$ due to surgical complications. The main ocular conditions which limited visual recovery were the presence of corneal opacities, hypermaturity of cataract, advanced glaucoma, senile macular degeneration, diabetic retinopathy, and postoperative retinal detachment in this order of frequency. The prevalence of these disorders in cataract patients among the Arab population was identified and is discussed.

The visual outcome and complication rate are the objective means of assessing the success of cataract surgery. ${ }^{12}$ While modern cataract extraction is safe and effective, irreversible blindness either from the complications of advanced untreated cataract or from the complications of surgery may occur. ${ }^{3}$ In addition associated ocular diseases increase the risk of complications and reduce the chances of a good visual outcome. ${ }^{4}$

The purpose of this article is to identify the main causes of poor visual achievement after cataract extractions in an Arab population in Kuwait, to highlight associated ocular problems with senile cataract, and to provide data about the prevalence of different eye disorders in this community.

\section{Materials and methods}

Four hundred and nine consecutive idiopathic (senile and presenile) cataract extractions in 352 patients were performed in the year 1983 at the Eye Department, lbn Sina Hospital, Kuwait. Other types of secondary or traumatic cataracts were excluded.

A complete ophthalmic examination was carried out when each patient was admitted. Operations were performed by several surgeons with various levels of experience. There were 329 intracapsular cataract extractions $(80 \cdot 4 \%)$ and $80(19 \cdot 5 \%)$ extra-

Correspondence to Dr Mahmoud Al Salem, FRCS, PO Box 43385 Hawalli, 32048, Kuwait. capsular extractions in this series. Optical correction was achieved by aphakic spectacles in $97.8 \%$ of cases. Only $2 \cdot 2 \%$ of cases had either soft contact lenses or intraocular lens implants.

Of the 409 eyes $385(94 \cdot 1 \%)$ had a satisfactory follow-up for a minimum period of one year. The best corrected visual acuity achieved after 12 to 18 months of follow-up was recorded, and a complete ophthalmic examination was conducted. The causes of visual acuity of $6 / 18$ or less were determined where possible. The results were analysed and considered in relation to the prevalence of ocular disorders diagnosed preoperatively.

\section{Results}

Table 1 shows the age and sex distribution of 352 patients. Their ages varied from 34 to 95 years, mean $58 \cdot 4$. The male to female ratio was $1 \cdot 3: 1$.

Table 1 Age and sex distribution of 352 cataract patients

\begin{tabular}{lcccc}
\hline Age groups & Male & Female & Total & Percentage \\
\hline Under 40 & 9 & 7 & 16 & $4 \cdot 5$ \\
$40-49$ & 41 & 19 & 60 & 17 \\
$50-59$ & 72 & 56 & 128 & $36 \cdot 4$ \\
$60-69$ & 48 & 45 & 93 & $26 \cdot 4$ \\
$70-79$ & 22 & 24 & 46 & $13 \cdot 1$ \\
$80-89$ & 4 & 3 & 7 & 2 \\
$90+$ & 2 & 0 & 2 & $0 \cdot 6$ \\
Total & 198 & 154 & 352 & 100 \\
\hline
\end{tabular}


Table 2 The visual acuities achieved after cataract extractions in 385 eyes

\begin{tabular}{lrc}
\hline Visual acuity & $n$ & Percentage \\
\hline 6/12 or better & 208 & $54 \cdot 0$ \\
6/18-6/36 & 108 & $28 \cdot 0$ \\
6/60-CF & 60 & $15 \cdot 6$ \\
HM-LP & 6 & $1 \cdot 5$ \\
No LP & 3 & 0.8 \\
\hline
\end{tabular}

$\mathrm{CF}=$ Counting fingers. $\mathrm{HM}=$ Hand movements.

$\mathrm{LP}=$ Light perception.

Table 2 shows the visual acuities achieved after 12 to 18 months of cataract extraction in 385 eyes. Of these, 208 eyes $(54 \%)$ achieved a visual acuity of $6 / 12$ or better and 177 eyes $(46 \%)$ achieved $6 / 18$ or less. Examination revealed that 127 out of 177 eyes $(71.7 \%)$ had poor vision due to preoperative ocular disorders, and 31 eyes $(15 \cdot 8 \%)$ had poor vision due to surgical complications. There were 19 eyes $(10.7 \%)$ that had visual failure due to multiple or undefined factors.

Table 3 shows the various preoperative ocular conditions which were responsible for poor visual achievement in 127 eyes. Corneal pathology, such as climatic droplet keratopathy (CDK) and trachomatous corneal scarring, represented $40.9 \%$ of cases. Optic nerve pathology was due to advanced glaucoma of a primary nature or lens induced. Macular and retinal diseases constituted $25.9 \%$ of cases. $66 \%$ of cases had $6 / 18$ to $6 / 36$ vision and $34 \%$ between $6 / 60$ to fingers counting vision. There were no cases that had less than fingers counting vision in this group.

Table 4 shows long term surgical complications

Table 3 The associated ocular disorders responsible for visual acuity of $6 / 18$ or less after cataract extraction

\begin{tabular}{|c|c|c|c|c|}
\hline Ocular disorder & $\begin{array}{l}6 / 18- \\
6 / 36\end{array}$ & $\begin{array}{l}6 / 60- \\
C F\end{array}$ & $\begin{array}{l}H M-\quad N o L P \\
L P\end{array}$ & Percentage \\
\hline $\begin{array}{l}\text { Opaque cornea } \\
\text { (trachoma + climatic } \\
\text { droplet keratopathy } \\
\text { + etc) }\end{array}$ & 43 & 9 & & $40 \cdot 9$ \\
\hline Lens induced glaucoma & 9 & 13 & & $17 \cdot 3$ \\
\hline $\begin{array}{l}\text { Advanced primary } \\
\text { glaucoma }\end{array}$ & 5 & 10 & & $11 \cdot 8$ \\
\hline $\begin{array}{l}\text { Senile macular } \\
\text { degeneration }\end{array}$ & 10 & 4 & & $11 \cdot 0$ \\
\hline Diabetic retinopathy & 7 & 3 & & $7 \cdot 8$ \\
\hline $\begin{array}{l}\text { Retinal degeneration: } \\
\text { (myopia+retinitis } \\
\text { pigmentosa, etc) }\end{array}$ & 7 & 2 & & $7 \cdot 1$ \\
\hline Amblyopia & 3 & & & $2 \cdot 4$ \\
\hline $\begin{array}{l}\text { Optic atrophy } \\
\text { (? aetiology) }\end{array}$ & & 2 & & 1.8 \\
\hline Total (127 eyes) & 84 & 43 & & $100 \cdot 1$ \\
\hline
\end{tabular}

Table 4 The surgical complications responsible for visual acuity of $6 / 18$ or less after cataract extractions

\begin{tabular}{|c|c|c|c|c|c|}
\hline Complication & $\begin{array}{l}6 / 18- \\
6 / 36\end{array}$ & $\begin{array}{l}6 / 60- \\
C F\end{array}$ & $\begin{array}{l}H M- \\
L P\end{array}$ & No $L P$ & Percentage \\
\hline Retinal detachment & 3 & 3 & 2 & 2 & $32 \cdot 3$ \\
\hline $\begin{array}{l}\text { Vitreous haemorrhage } \\
\text { and opacities }\end{array}$ & 2 & 4 & 2 & & $25 \cdot 8$ \\
\hline After cataract & 5 & & & & 16 \\
\hline $\begin{array}{l}\text { Cystoid macular } \\
\text { oedema }\end{array}$ & 1 & 2 & & & 9.7 \\
\hline $\begin{array}{l}\text { Infection } \\
\quad \text { (endophthalmitis) }\end{array}$ & & & 2 & 1 & $9 \cdot 7$ \\
\hline $\begin{array}{l}\text { Decompensated } \\
\text { corneas }\end{array}$ & 2 & & & & $6 \cdot 4$ \\
\hline Total ( 31 eyes) & 13 & 9 & 6 & 3 & \\
\hline
\end{tabular}

that resulted in a visual failure in 31 eyes. Of the 10 cases of retinal detachment (32.3\% of cases) all had at least one operation for the condition, and retinal attachment was achieved in six eyes $(60 \%)$. Organised vitreous heamorrhage due to combined surgical hyphaema and vitreous loss occured in five eyes, where blood entered the posterior segment from within the anterior compartment, and also opaque media after severe postoperative inflamatory reactions occurred in three other cases. Nine cases $(29 \%)$ in this group (Table 4) had hand movements to no light perception.

Nineteen eyes with poor vision which could not be attributed to a main causative factor were found to have a combination of opaque cornea, raised intraocular pressure, and vitreous opacities.

Table 5 shows the prevalence of ocular disorders associated with senile cataract as diagnosed at the

Table 5 The pre-existing ocular disorders associated with senile cataract in 385 eyes of Kuwaiti Arab patients

\begin{tabular}{lrrrr}
\hline Ocular disorder & $M$ & $F$ & Total Percentage \\
\hline Corneal pathology: & & & & \\
$\quad$ Droplet keratopathy & 33 & 13 & 46 & 11.9 \\
$\quad$ Trachomatous corneal scarring & 10 & 16 & 26 & $6 \cdot 7$ \\
$\quad$ Non-specific corneal scarring & 9 & 5 & 14 & $3 \cdot 6$ \\
$\quad$ Cornea guttata & 4 & 7 & 11 & $2 \cdot 8$ \\
Complications of hypermaturity: & & & & \\
$\quad$ Phacomorphic glaucoma & 8 & 19 & 27 & $7 \cdot 0$ \\
$\quad$ Phacolytic glaucoma & - & 2 & 2 & $0 \cdot 5$ \\
$\quad$ Subluxated lens & 2 & - & 2 & $0 \cdot 5$ \\
Glaucoma: & 1 & 4 & 5 & 1.3 \\
$\quad$ Neglected closed angle & 1 & 2 & 3 & $0 \cdot 8$ \\
$\quad$ Chronic primary closed angle & 3 & 2 & 5 & $1 \cdot 3$ \\
$\quad$ Controlled open angle & 1 & 2 & 3 & $0 \cdot 8$ \\
$\quad$ Advanced open angle & 12 & 11 & 23 & 5.9 \\
Pseudoexfoliation & 2 & 1 & 3 & $0 \cdot 8$ \\
Strabismic amblyopia & 3 & - & 3 & $0 \cdot 8$ \\
High myopia & 4 & 2 & 6 & 1.6 \\
Diabetic retinopathy & 93 & 86 & 179 & 46.5 \\
Total & & & & \\
\hline
\end{tabular}


time of admission in 385 eyes, as well as the distribution of each disorder according to sex.

One hundred and seventy-nine eyes $(46.5 \%)$ had some sort of ocular disorder when presenting for cataract extraction. In 97 eyes $(25 \cdot 2 \%)$ there were significant corneal opacities. Climatic droplet keratopathy represented $47.4 \%$ of corneal pathology and $11.9 \%$ prevalence among the cataract population in Kuwait; trachomatous corneal scarring represented $26.8 \%$ of total corneal pathology and $6.7 \%$ prevalence in the cataract population.

Hypermature cataractous lenses were present in 31 eyes $(8 \%)$ when first seen. Twenty-nine of these patients presented because of ocular pain due to lens induced glaucoma. All cases had unilateral mature cataract in one eye and good visual acuity in the fellow eye. Lens induced glaucoma was more common in females, with a male to female ratio of 1:2.1.

Advanced glaucoma were found in 16 eyes $(4 \cdot 2 \%)$. There was equal prevalence of primary chronic closed angle glaucoma and simple open angle glaucoma. Chronic closed angle glaucoma showed a higher incidence in females, 6 out of 8 eyes $(75 \%)$. Pseudoexfoliation was noted in 23 patients $(5.9 \%)$ but was not associated with raised intraocular pressure.

\section{Discussion}

The visual outcome after cataract extraction in a selected series of patients with senile cataract was $6 / 12$ or better in $81.6 \%$ of cases. ${ }^{2}$ But the presence of identifiable eye disease besides the cataract increases the risk of operative complications and reduces the visual prognosis. ${ }^{4}$ In a review of 500 cataract extractions by Chandler and Wadsworth $5.4 \%$ of eyes had no improvement of vision owing to pre-existing ocular conditions such as macular changes, optic atrophy, or retinal detachment. The prevalence of senile macular degeneration in a cataract population was $13.2 \%$ in one study. ${ }^{2}$ Further, the higher incidence of both cataract and macular degeneration in older people ${ }^{6}$ makes the coexistence of the two conditions very likely. It has been found that the preoperative factor which mainly influences the outcome of cataract surgery is the presence or absence of macular disease. ${ }^{7}$ While this holds true in developed countries, there are other limiting factors in developing communities that were not identified. In a study of 567 cataract extractions in Nigerians ${ }^{8}$ the visual acuity achieved was recorded in only $49 \cdot 2 \%$ of that series, and there was no mention of associated ocular disease.

Meredith and Maumenee classified cataract patients into three groups ${ }^{4}$ : group 1, no preoperative factors predisposing to complication; group 2, visual improvement was hoped for, but not expected; and group 3, those eyes predisposed to operative or postoperative complications. The last two groups constituted $32.4 \%$ of eyes in their series,${ }^{4}$ but in our series $46.5 \%$ of the eyes fell in the last two groups.

If cases of opaque cornea and glaucoma were excluded from our series, $71.5 \%$ of cases would achieve $6 / 12$ or better. Preoperative ocular diseases were found to be responsible for $77 \cdot 1 \%$ of cases with visual failure after surgery in this series. Corneal opacities were the leading cause of poor visual outcome $(41 \%)$. Trachomatous corneal opacities and climatic droplet keratopathy were found separately or more frequently combined. Climatic droplet keratopathy ${ }^{9}$ is also known as Labrador keratopathy, ${ }^{10}$ spheroidal degeneration of cornea, ${ }^{11}$ and desert keratopathy in this part of the world. It is three times more frequent in males than females and also more severe. Because of its location in the central part of the cornea and the irregularity of the surface epithelium it frequently results in visual deterioration. Though vision is usually somewhat reduced $(6 / 18-6 / 36)$, the disease occasionally produces profound visual failure, especially in association with trachomatous corneal scaring. Droplet keratopathy is related to ultraviolet radiation, ${ }^{12}$ and females may be protected by wearing veils in this part of the world $^{13}$ or by being less exposed to sunlight, as they tend not to go outdoors as males do.

Though acute trachoma infections are infrequently seen among Kuwaitis now, the complications of healed trachoma are nevertheless commonly seen in older people. Cloudy to hazy corneas due to trachomatous corneal scarring, with variable degrees of dry eyes and eyelid malpositions, are daily seen in outpatient practice in the older population.

This situation necessitated a modification of preoperative and operative techniques. Patients frequently had lid surgery or rubbing lashes dealt with first. They might need frequent artificial tear drops before and after surgery. Fornix based conjunctival flaps became more popular, as it is easier to approach the limbus and avoid a scarred superior bulbar conjunctiva in limbal based flaps. Moreover the high incidence of opaque corneas and mature cataracts delayed the popularity of planned extracapsular cataract extraction techniques.

The second problem was the high incidence of lens induced glaucomas (phacomorphic and phacolytic). They were responsible for $17 \cdot 3 \%$ of cases with visual failure after cataract surgery. In this group 21 out of 29 eyes $(72.4 \%)$ failed to achieve good vision. Only eight eyes $(27 \cdot 5 \%)$ were able to achieve $6 / 12$ or better. All the patients had good visual acuity in the fellow eyes. This observation may explain the delay in seeking medical help. 
The third problem was neglected or inadequately treated glaucomas when patients did not seek proper medical care early enough or did not comply with the treatment. The visual achievement of those eyes was unsatisfactory on the whole ( 15 out of 16 eyes $(93.7 \%)$ achieved 6/18 vision or less). Seven cases $(43.7 \%)$ had combined glaucoma and cataract surgery.

Senile macular degeneration has a lower incidence among the cataract population in Kuwait $(3.6 \%)$ than in Americans and Europeans ${ }^{67}$ in the same age groups. Though senile macular degeneration was responsible for $11 \%$ of poor visual outcome after surgery, it was of mild degree. Ten out of 14 eyes $(71 \%)$ had 6/18 to 6/36 vision. No cases with discform macular lesions were seen. All cases were of dry type.

Pseudoexfoliation was seen in $5.9 \%$ in this series in contrast to a higher incidence in Australian Aborigines ${ }^{14}$ and a lower incidence in Americans. ${ }^{15}$

All amblyopic and strabismic eyes were identified preoperatively. Three out of 6 myopic eyes with myopic chorioretinal degeneration were identified, but none of the eyes with senile macular degeneration were suspected.

It is of interest to note that visual failure due to preoperative factors did not reduce visual acuity beyond fingers counting, but serious surgical complications did. Six of 31 eyes with surgical complications had hand movements to light perception and three eyes had no light perception.

The surgical complication rate for the whole series as regards retinal detachment (10 eyes), $2 \cdot 6 \%$, and endopththalmitis (three eyes) $0.7 \%$ correlates well with internationally reported figures. ${ }^{416} 17$ Noteworthy is the higher incidence of cataract extraction in younger people (Table 1$) ; 21.5 \%$ of patients were under 50 and $57.6 \%$ of patients were under 60 . Such an observation needs further investigation in future studies.

Finally, we recommend earlier extraction of cataract to avoid the complication of hypermaturity, serious consideration of combined keratoplasty and cataract extraction when opaque cornea is thought to be a limiting factor for visual recovery, and the development of more experience in closed intraocular microsurgery (vitrectomy) to reduce the long term sequelae of surgical complications.

\section{References}

1 Vennon S, Cheng H. Comparison between the complications of cataract surgery following local anaesthesia with short stay and general anaesthesia with a five day hospitalisation. $\mathrm{Br} J$ Ophthalmol 1985; 69: 360-3.

2 Bernth-Petersen $P$. Outcome of cataract surgery. I. A prospective, observational study. Acta Ophthalmol (Kbh) 1982; 60: 235-42.

3 Sommer A. Cataracts as an epidemiologic problem. Am J Ophthalmol 1977; 83: 334-9.

4 Meredith T, Maumenee E. Review of 1000 cases of intracapsular cataract extractions: I. Complications. Ophthalmic Surg 1979; 10: $32-41$

5 Chandler A, Wadsworth J. Cataract surgery: review of 500 consecutive cases. Ann Ophthalmol 1975; 8: 1597-602.

6 Klein B, Klein R. Cataracts and macular degeneration in older Americans. Arch Ophthalmol 1982; 100: 571-3.

7 Bernth-Petersen P. Outcome of cataract surgery III. Influence of age, macular disease and type of correction. Acta Ophthalmol (Kbh) 1982; 60: 455-60.

8 Osuntokun O, Olurin P. Cataract and cataract extractions in Nigerians: an evaluation of 567 extractions. $\mathrm{Br} \mathrm{J} \mathrm{Ophthalmol}$ 1978; 57: 27-33.

9 Freedman A. Climatic droplet keratopathy: I. Clinical aspects. Arch Ophthalmol 1973; 89: 193-7.

10 Freedman A. Labrador keratopathy. Arch Ophthalmol 1965; 74: 198-202.

11 Garnev A, Fraunfelder FI, Barras TC, Hinzpeter EN. Spheroidal degeneration of cornea and conjunctiva. $\mathrm{Br} J$ Ophthalmol 1976; 60: 473-8.

12 Taylor H. Aetiology of climatic droplet keratopathy and pterygium. BrJ Ophthalmol 1980; 64: 154-63.

13 Tabbara K. Climatic droplet keratopathy. Proceeding of symposium on new developments in ophthalmology. King Khalid Eye Specialist Hospital, Riyadh, Saudi Arabia, 1984: 1: 55-60.

14 Taylor H. The environment and the lens. Br J Ophthalmol 1980; 64: 303-10.

15 Rita H, Sperduto R, Kureger E. Pseudoexfoliation, intraocular pressure and senile lens changes in a population based survey. Arch Ophthalmol 1982; 100: 1080-2.

16 Bellow J, Bellows R. Complications of cataract surgery. In Bellow J, ed. Cataract and abnormalities of the lens. New York: Grune and Stratton, 1975: 484-91.

17 Allen H. Bacterial endophthalmitis after cataract surgery. In: Bellow J, ed. Cataract and abnormalities of the lens. New York: Grune and Stratton, 1975: 421-8.

Accepted for publication 31 July 1986. 